\title{
PERAN PENASIHAT AKADEMIK (PA) DALAM MENINGKATKAN HASIL BELAJAR MAHASISWA MAHASISWI PROGRAM STUDI DIPLOMA TIGA KEBIDANAN STIKES DHARMA HUSADA BANDUNG
}

\author{
Dian Purnama Sari ${ }^{1)}$, Nurlelah Aprilia S. Iskandar ${ }^{2)}$ \\ Program Studi Diploma Tiga Kebidanan STIKes Dharma Husada Bandung \\ dians1552@gmail.com
}

\begin{abstract}
A B S T R A K
Dalam melaksanakan kewajiban mahasiswa perlu mendapatkan haknya sehingga terjadi keseimbangan antara hak dan kewajiban yang telah tertulis dalam Tata Tertib Pergaulan Mahasiswa di Kampus untuk menghindari mahasiswa dalam terlibat masalah selama proses perkualihan. Permasalahan akademik yang dihadapi mahasiswa tidak hanya mencakup tentang pengesahan dan konsultasi FRS, tetapi juga menyangkut permasalahan pribadi mahasiswa dalam menjalankan pembelajaran misalnya penurunan hasil belajar, kesulitan dalam menerima pembelajaran atau masalah seputar motivasi belajar. Oleh karena itu, pihak intsitusi memberikan tugas kepada setiap dosen sebagai pembimbing atau Penasihat Akademik (PA). Seorang PA harus mampu memberikan solusi untuk permasalahan mahasiswa tersebut. Penelitian bertujuan mengetahui peran penasihat akademik (PA) dalam peningkatan prestasi belajar mahasiswi Program Studi Diploma Tiga Kebidanan STIKes Dharma Husada Bandung. Metode penelitian adalah kuantitatif. Subjek penelitian kuantitatif adalah 86 dan kualitatif 42 informan secara simple random sampling. Penelitian dilakukan di STIKes Dharma Husada Bandung pada bulan Maret 2019. Uji analisis menggunakan uji Pearson. Hasil penelitian ada hubungan antara peran pembimbing akademik dengan prestasi belajar mahasiswa $(\mathrm{p}=0,000)$. Simpulan, frekuensi, kualitas bimbingan akademik, dan motivasi belajar mahasiswa baik sesuai panduan bimbingan akademik mahasiswa, upaya dosen pembimbing akademik dalam meningkatkan motivasi, serta hasil yang telah dicapai dari pelaksanaan layanan bimbingan belajar baik,
\end{abstract}

Kata kunci: bimbingan akademik, mahasiswa, kebidanan, motivasi belajar, prestasi belajar.

\section{PENDAHULUAN}

Pendidikan merupakan salah satu aspek sangat penting untuk diperhatikan guna meningkatkan kualitas sumber daya manusia. Mahasiswa yang menuntut ilmu di STIKes Dharma Husada Bandung memiliki tingkat kecerdasan yang berbeda baik intelektual ataupun secara emosional. Hal tersebut dibuktikan dengan beragamnya tingkat Indeks Prestasi (IP) yang diperoleh mahasiswa. Selain itu, mereka memiliki latar belakang budaya dan lingkungan yang berbeda.
Dalam melaksanakan kewajiban mahasiswa perlu mendapatkan haknya sehingga terjadi keseimbangan antara hak dan kewajiban yang telah tertulis dalam Tata Tertib Pergaulan Mahasiswa di Kampus untuk menghindari mahasiswa dalam terlibat masalah selama proses perkualihan. Permasalahan akademik yang dihadapi mahasiswa tidak hanya mencakup tentang pengesahan dan konsultasi FRS, tetapi juga menyangkut permasalahan pribadi mahasiswa dalam menjalankan pembelajaran misalnya penurunan hasil belajar, kesulitan dalam menerima pembelajaran atau masalah 
seputar motivasi belajar. Oleh karena itu, pihak intsitusi memberikan tugas kepada setiap dosen sebagai pembimbing atau Penasihat Akademik (PA). Seorang PA harus mampu memberikan solusi untuk permasalahan mahasiswa tersebut.

Bimbingan akademik merupakan bentuk layanan bimbingan konseling dalam setting pendidikan yang diberikan kepada pelajar atau peserta didik yang berkenaan dengan sikap dan kebiasaan belajar, materi belajar, kesulitankesulitan dalam belajar guna mencapai tujuan yang diinginkan dari kegiatan belajarnya tersebut.

Motivasi belajar adalah sebuah dorongan yang berada dalam diri mahasiswa untuk mengarahkan aktivitas belajar sehingga mencapai tujuan yang diinginkan. Dalam motivasi belajar dorongan merupakan kekuatan mental untuk melakukan kegiatan dalam rangka pemenuhan harapan dan dorongan dalam hal ini adalah pencapaian tujuan.

Motivasi belajar pada diri setiap orang memegang peranan yang sangat penting dalam kegiatan belajar di perguruan tinggi. Motivasi dipengaruhi tujuan yang akan dicapai dengan belajar. Makin tinggi tujuan belajar, semakin besar pula motivasinya, semakin besar motivasi belajarnya akan semakin kuat pula kegiatan belajarnya.

\section{METODE PENELITIAN}

Metode penelitian menggunakan metode kuantitatif. Jumlah sampel 42 orang dengan teknik random sampling.
Data sekunder diperoleh melalui daftar IPK dan buku bimbingan akademik. Instrumen ini digunakan untuk memperoleh data yang berupa dokumen dari akademik, baik itu berupa daftar nama-nama penasehat akademik, jumlah mahasiswa, serta indeks prestasi kumulatif (IPK) mahasiswa. Dokumentasi dilakukan untuk mengumpulkan data mengenai variabel terikat prestasi Belajar mahasiswa dan kegiatan bimbingan akademik. Data primer diperoleh melalui kuesioner. Kuesioner diberikan kepada mahasiswa sebagai subjek penelitian sesuai jumlah sampel (42 orang). Kuesioner digunakan untuk mendapatkan informasi mengenai proses bimbingan akademik. Penelitian dilaksanakan pada bulan Maret 2019 di STIKes Dharma Husada Bandung.

\section{HASIL}

Penelitian melibatkan 42 orang subjek. Pengumpulan data kuantitatif melibatkan subjek yang memenuhi kriteria inklusi. Data yang didapat menggunakan kuesioner, dilakukan uji normalitas dengan hasil data tersebut berdistribusi normal, selanjutnya dilakukan uji analisa menggunakan Uji Pearson. Berdasar atas hasil penelitian menggunakan kuesioner kepada mahasiswa semester IV Program Studi Diploma Tiga Kebidanan STIKes Dharma Husada Bandung mengenai proses bimbingan akademik didapatkan hasil sebagai berikut: 
Tabel 1 Distribusi Frekuensi Peran Pembimbing Akademik Mahasiswa Semester IV Program Studi Diploma Tiga Kebidanan

\begin{tabular}{lrrrr}
\hline Variabel & Frequency & Percent & $\begin{array}{c}\text { Valid } \\
\text { Percent }\end{array}$ & $\begin{array}{c}\text { Cumulative } \\
\text { Percent }\end{array}$ \\
\hline Peran pembimbing akademik & & & & \\
Baik & 1 & 2,4 & 2,4 & 2,4 \\
Cukup & 37 & 88,1 & 88,1 & 90,5 \\
Kurang & 4 & 9,5 & 9,5 & 100,0 \\
Total & 42 & 100,0 & 100,0 & \\
\hline
\end{tabular}

Berdasar atas Tabel 1 tentang peran pembimbing akademik mahasiswa paling banyak memiliki peran cukup, yaitu 37 mahasiswa $(88,1 \%)$. Peran pembimbing akademik yang baik dinyatakan paling sedikit yaitu $1(2,4 \%)$.

Tabel 2 Distribusi Frekuensi Prestasi Mahasiswa semester IV Program Studi Diploma Tiga Kebidanan

\begin{tabular}{lrrrr}
\hline Variabel & Frequency & Percent & $\begin{array}{c}\text { Valid } \\
\text { Percent }\end{array}$ & $\begin{array}{c}\text { Cumulative } \\
\text { Percent }\end{array}$ \\
\hline Prestasi mahasiswa & & & & \\
Memuaskan & 41 & 97,6 & 97,6 & 97,6 \\
Sangat Memuaskan & 1 & 2,4 & 2,4 & 100,0 \\
$\quad$ Total & 42 & 100,0 & 100,0 & \\
\hline
\end{tabular}

Berdasar atas Tabel 2 tentang prestasi belajar mahasiswa paling banyak memiliki predikat memuaskan, yaitu 41 mahasiswa
$(97,6 \%)$. Predikat sangat memuaskan sebanyak 1 mahasiswa $(2,4 \%)$.

Tabel 3 Hubungan Peran Pembimbing Akademik (PA) dengan Prestasi Mahasiswa Semester IV Program Studi Diploma Tiga Kebidanan

\begin{tabular}{lccc}
\hline & Value & df & $\begin{array}{c}\text { Asymptotic Significance } \\
(2-\text { sided })\end{array}$ \\
\hline Pearson Chi-Square & $42,000^{\mathrm{a}}$ & 2 & 0,000 \\
Likelihood Ratio & 9,451 & 2 & 0,009 \\
Linear-by-Linear & 10,075 & 1 & 0,002 \\
Association & 42 & & \\
N of Valid Cases & & \\
\hline
\end{tabular}

Berdasar atas Tabel 3 terdapat perbedaan nilai pengetahuan rerata ibu balita sebelum dengan sesudah implementasi anjungan mandiri posyandu (AMP) $(\mathrm{p}=0,001)$. Persepsi ibu balita sebelum dengan sesudah implementasi AMP juga berbeda $(\mathrm{p}=0,004)$.

Berdasar atas Tabel 4.3 menunjukkan bahwa nilai signifikansi sebesar 0,000 dengan demikian probabilitas (signifikansi) lebih kecil 
dari $0,05(0,000<0,05)$, maka ada hubungan antara peran pembimbing akademik dengan prestasi belajar mahasiswa..

Hasil pengujian keterkaitan antar kedua variabel ini melalui uji Chi-Square, dimana diperoleh nilai dengan nilai signifikansi (Asymp. Sig. (2-sided)) sebesar 0,000. Berdasarkan hasil yang telahdiperoleh, terlihat bahwa nilai $\chi 2$ nilai

\section{PEMBAHASAN}

\section{Bimbingan Mahasiswa oleh Dosen Penasihat Akademik (PA)}

Program Studi Diploma Tiga Kebidanan telah berusaha memenuhi hak mahasiswa dalam hal pelaksanaan pendidikannya di perguruan tinggi sesuai dengan yang tercantum dalam buku saku Etika dan Tata Tertib Bimbingan rutin mahasiswa dilakukan pada saat perwalian atau konsultasi format rencana studi (FRS), termasuk mata kuliah yang di remidi pada semester sebelumnya, dan mahasiswa diberikan motivasi dan pengarahan secara berkelompok atau secara individu. Hal ini sesuai dengan fungsi dan tujuan bimbingan menurut yakni mengarahkan para mahasiswa kepada program pendidikan profesional di perguruan tinggi dan membantu para mahasiswa merencanakan program studinya agar berhasil. Pendapat ini didukung oleh perincian tugas PA yang termuat dalam buku panduan pembimbingan akademik STIKes Dharma Husada Bandung bahwa PA memberikan bimbingan (motivasi, signifikansi $(0.000)<\alpha \quad(0,05)$ sehingga $\mathrm{H} 0$ ditolak. Sehingga dapat disimpulkan bahwa terdapat hubungan antara peran bimbingan akademik dengan peningkatan prestasi mahasiswa mahasiswa semester IV Program Studi Diploma Tiga Kebidanan STIKes Dharma Husada Bandung.

penjelasan, arahan, nasihat) kepada mahasiswa bimbingannya yang berkaitan dengan persoalan akademis.

Secara keseluruhan bimbingan mahasiswa telah dilakukan mengarah pada perbaikan dan peningkatan kualitas pengetahuan dan kepibradian mahasiswa sehingga akan meningkatkan pendidikan.

\section{Upaya Dosen Penasihat Akademik (PA) dalam Meningkatkan Hasil Belajar Mahasiswa}

Semua dosen Penasihat Akademik (PA) selalu berusaha melakukan pemantauan terhadap perkembangan hasil belajar mahasiswa bimbingannya. Hasil belajar yang dimaksud adalah indeks prestasi (IP) yang diperoleh mahasiswa sebagai hasil belajarnya tiap semester dan indeks prestrasi kumulatif (IPK) sebagai keseluruhan hasil belajar yang diperoleh atas belajar yang telah ditempuh. Menurut buku peraturan akademik STIKes Dharma Husada Bandung, IP adalah nilai rerata hasil belajar yang menggambarkan 
pencapaian kompetensi mahasiswa untuk semester tertentu.

Pemantauan hasil belajar yang dilakukan pada umumnya dengan membuat catatan tentang materi bimbingan mahasiswa yang terkumpul dalam sebuah buku besar yang dimiliki masing-masing dosen PA maupun mahasiswa. Hal ini dilakukan untuk dapat mengontrol dan mengetahui hasil belajar yang dicapai oleh setiap mahasiswa bimbingannya. Selain buku tersebut, para dosen PA dapat melakukan pemantauan melalui Sistem Informasi Akademik (SIAKAD). Indeks prestasi yang diperoleh mahasiswa menentukan jumlah SKS yang diambil untuk semester yang akan datang. Seperti yang terdapat Peraturan Akademik DHB, Penasihat Akademik mempertimbangkan jumlah SKS yang diambil oleh mahasiswanya untuk semester yang akan dijalani berdasarkan IP yang dicapai pada semester sebelumnya sesuai dengan ketentuan yang berlaku.

Berdasarkan data penelitian bahwa dosen PA memberikan motivasi, pertimbangan pengambilan mata kuliah dan pemanggilan mahasiswa dalam rangka mempertahankan dan meningkatkan IP yang diraih oleh mahasiswa bimbingannya. Secara keseluruhan dosen PA telah berusaha sesuai dengan kemampuan dan waktu yang dimiliki dosen PA disela kesibukannya. Selain upaya tersebut dengan mengulang mata kuliah yang dirasa dapat meningkatkan IPK yang dicapai digunakan sebagai cara untuk memperbaiki nilai yang telah diperoleh.

Upaya peningkatan dengan bimbingan dosen PA akan berhasil apabila dari pihak mahasiswa juga berupaya untuk meningkatkan hasil belajarnya. Tidak hanya tergantung pada bimbingan yang diberikan, tetapi keseimbangan antara bimbigan dan ketekunan belajar mahasiswa dapat meningkatkan hasil belajar yang dicapai mahasiswa.

3. Hasil yang Telah Dicapai dari Pelaksanaan Layanan Bimbingan Akademik dalam Meningkatkan Motivasi Belajar Mahasiswa

Setelah melakukan serangkaian penelitian untuk mengetahui hubungan peran pembimbing akademik terhadap peningkatan prestasi belajar mahasiswa, diketahui bahwa seluruh mahasiswa telah melaksanakan bimbingan akademik namun belum seluruhbya sesuai dengan ketentuan yang tertera pada Standar operasional prosedur STIKes Dharma Husada Bandung.

Artinya bimbingan akademik termasuk dalam kualifikasi cukup dalam pengaruhnya terhadap peningkatan prestasi belajar. Berdasarkan hasil sebaran kuesioner mengenai bimbingan akademik, ada beberapa hal terkait bimbingan akademik yang perlu ditingkatkan, seperti: Penasehat Akademik harus mengevaluasi hasil kuliah semester sebelumnya serta memberikan bimbingan akademik untuk semester selanjutnya setiap 
awal semester. Selain itu, Penasehat Akademik juga harus selalu memantau keadaan mahasiswa bimbingannya minimal 3 kali dalam satu semester. Sementara hal-hal yang perlu dipertahankan seperti: Penasehat Akademik selalu memberikan bimbingan, arahan, dan saran, Penasehat Akademik selalu menetapkan dan mengumumkan jadwal bimbingan setiap awal semester, serta Penasehat Akademik sering menanyakan proses dan keadaan Akademik mahasiswa bimbingannya.

Berdasarkan dokumentasi prestasi belajar mahasiswa Program Studi Diploma Tiga Kebidanan, maka dapat digambarkan bahwa prestasi belajar mahasiswa berada dalam 3 kategori yakni memuaskan, sangat memuaskan dan dengan pujian. Mahasiswa yang nilainya berada pada kategori memuaskan yakni 41 mahasiswa $(97,6 \%)$. Mahasiswa yang nilainya berada pada kategori sangat memuaskan yakni 1 mahasiswa $(2,4 \%)$. Mahasiswa yang nilainya berada pada kategori dengan pujian yakni tidak ada (0\%). Berdasarkan hasil pengujian hipotesis diperoleh nilai Asymptotic Significance $(2$-sided $)=0,000$, maka

\section{SIMPULAN}

Peran bimbingan akademik berhubungan dengan peningkatan prestasi mahasiswa mahasiswa. Bimbingan akademik dan motivasi belajar mahasiswa ditinjau dari sisi frekuensi dan kualitas dilakukan dengan baik sesuai
$0,000<0,05$ maka dapat disimpulkan bahwa H0 ditolak. Jadi kesimpulannya, terdapat hubungan peran pembimbing akademik dengan prestasi belajar mahasiswa.

Kesimpulan ini selaras dengan teori yang dikemukakan Rochman Natawidjaja bahwa bimbingan membantu individu mencapai perkembangan diri secara optimal sebagai makhluk sosial. Hal tersebut selaras pula dengan tujuan bimbingan akademik yaitu membantu mahasiswa agar dapat menyelesaikan studi tepat pada waktunya dengan hasil yang memuaskan. Dengan terdapat hubungan peran pembimbing akademik dengan prestasi belajar mahasiswa, diharapkan untuk pihak institusi perguruan tinggi dan civitas akademika bekerja sama agar senantiasa memperbaharui standar operasional prosedur (SOP) Pelaksanaan Bimbingan Akademik. Selain itu, pihak program studi harus bekerja sama dengan Penasehat Akademik untuk selalu mengontrol buku konsultasi bimbingan akademik sebagai bukti bahwa mahasiswa tersebut telah melaksanakan bimbingan akademik.

panduan bimbingan akademik mahasiswa, upaya dosen pembimbing akademik baik dalam meningkatkan motivasi belajar mahasiswa, dan hasil yang telah dicapai dari pelaksanaan layanan bimbingan akademik baik dalam meningkatkan motivasi belajar mahasiswa 


\section{DAFTAR PUSTAKA}

1. Sukmadinata, Syaodih N. Bimbingan dan Konseling Dalam Praktek. BANDUNG: MAESTRO; 2007.

2. Syamsu Yusuf, Juntika AN. Landasan Bimbingan dan Konseling. BANDUNG: PT Remaja Rosdakarya; 2005.

3. Hamalik O. Manajemen Belajar Di Perguruan Tinggi. BANDUNG: Sinar Baru Algensindo; 2003.

4. MKDP TP. Kurikulum dan Pembelajaran. BANDUNG: Rajawali Pers; 2011.

5. Budiani. Panduan Akademik Fakultas Tarbiyah dan Keguruan. YOGYAKARTA: UIN Sunan Kalijaga Yogyakarta; 2011.

6. Anonim. Penasihat Akademik dan Kewajiban Mahasiswa dalam Bimbingan Akademik [Internet]. 2012. Tersedia pada: http://fe.unisma.ac.id

7. Sudjana N. Dasar-Dasar Proses Belajar Mengajar. Bandung: Sinar Baru Algesindo; 2004.

8. Habsari S. Bimbingan dan Konseling SMA Untuk Kelas XI [Internet]. 2005. Tersedia pada: http://books.google.co.id

9. Maharyanti N. Pemanfaatan Layanan Pembimbing Akademik Oleh Mahasiswa Program Studi Pendidikan Administrasi Perkantoran Fakultas Ilmu Sosial dan Ekonomi Universitas Negeri Yogyakarta. Universitas Negeri Yogyakarta; 2007.

10. Sudarsono B. Tingkat Efektivitas Pemanfaatan Bimbingan Akademik Oleh Mahasiswa Teknik Otomotif Universitas Negeri Yogyakarta Angkatan Tahun 2006. Universitas Negeri Yogyakarta; 2007.

11. Suhardi. Pemanfaatan Penasihat Akademik Oleh Mahasiswa Fakultas Bahasa dan Seni Universitas Negeri Yogyakarta. J Cakrawala Pendidik. 2009;2(2):189-208.

12. Budiyanto SM. Pelaksanaan Tugas Dosen Pembimbing Akademik (PA) pada Program Studi Pendidikan Administrasi Perkantoran Fakultas Ilmu Sosial dan Ekonomi Universitas Negeri Yogyakarta. Universitas Negeri Yogyakarta; 2006. 